\title{
Ideal Child Rearing Practices By Educated Parents
}

\author{
Prof. Praveen Devgan \\ Faculty of Education, Dayalbagh Educational Institute, Dayalbagh, Agra-282010 (U.P.) India
}

\begin{abstract}
Though the concept of child rearing is as old as dawn of civilization, with time and advancement in technology and research these concepts are continuously in a state of flux with the result what was acceptable at a certain period of time may be regarded as out dated or irrelevant today and vice-versa, with this in view and to bring out the collective opinions of the professionals of different fields which are mainly involved in the growth and development of the child, the study was carried out by taking the interview of the experts. The descriptive analysis of the data and justification on the basis of collective opinions of experts of child rearing practices is given. The present study seeks to determine the practices followed by educated parents in rearing their children. It is observed that parents with high level of education tend to follow rigid rearing practices whereas parents with low level of education follow permissive rearing practices, only 46.67 per cent parents of all the groups were found to follow ideal rearing practices. It is found that education of parents plays a significant role in many aspects of child rearing practices.
\end{abstract}

Keywords - Education Level of Parents, Experts Opinion, Fuzzy Set, Rearing Practices, Socio-economic Status

\section{Introduction}

Child rearing is a tricky business, engaged in by all the parents, without much of empirical confirmations. The plasticity of human behaviour during the period of infancy and childhood affords a tremendous opportunity to parents and educators. The child lives in four worlds (1) The physico-economic world that affects the lives of its inhabitants by its climate, soil, and natural resources, and by its depressions, wars, and shifting values. (2) The culture the patterned ways of living that are characteristics of a given society. (3) The personal-social world of relationships, beginning with the family group and widening as the child grows older and (4) The private and personal world that is unique to each individual. Parental influences probably outweigh the effect of all other environmental impacts combined in determining the fundamental organization of children's behaviour. It plays a significant role in giving final shape to the child's physical fitness, emotional stability, learning skills and cognitive urge. The infant continuously pushes forward in every area of development-physical, emotional and intellectual. The strides that the baby makes in his first three years become the foundations of his growth and development as a person. Parents vary in their rearing practices and are frequently unpredictable. Their interactions with children are often tinged with odd combination of traditions, personal prejudices, emotional regards and rule of thumb procedure.

There have been shifts in attention that the various phases of child rearing practices have attracted during the past several years. However, during the past decade consistent efforts have been made in the study of development of the child through child rearing practices. The important contribution has been done in this direction by Sears, et al (1957), Buch et al (1962), Whiting (1963), Whiting \& Child (1977)] Mohan C. Joshi (1977), Pandey D.M. (1979), Roy G.S. (1980), Singh M.B. (1981), Cotterel John. L. (1985), de Borah (1985), Lowe Vandell \& Kathy Shores (1987). These Studies shows the impact of cross-culture, traditions, social environment, living standards, socio-economic status etc., upon the development of the child.

Studies also reveal that child rearing practices vary from country to country, State to State, caste to caste and cross-culturally. Few of the studies refer to the effect of living style and standards (urban and rural) of parents and the child rearing practices prevailing therein upon the development of the child. Hence it may also be visualized that the education level of the parent may also have a definite effect on the development of child and child rearing practices. No significant work has been attempted in this field so far. An attempt is being made through this research to analyze and compare the child rearing practices prevailing among educated parents.

The educational function of the family while perhaps not as comprehensive as in the past is still an important element. Parent's education is a part of home environment, the positive relationship of motivations to learning is universally accepted by both educators and behavioural scientists. In most perspective studies the single best predictor of later functioning was not parental status but the level of mother's education. In this study an attempt is made to study and analyze the broad spectrum (Nine aspects) of child rearing practices, using education of parents as a predictor.

The major purpose of the study is to find out if there is any difference in child rearing practices by 
parents of different levels of education. It is possible that highly educated parents may bring up their child in a better way than those at low level of education. The child comes into the world as a tender and delicate creature. He needs someone to nourish him with deligence and love and protect him from all harm. It is more important for parents to have a proper relationship with their children than to develop specific techniques to handle specific situations. A fundamental understanding of the child and the development of an affectionate, accepting attitude are more significant in solving specific training situations than any given set of rules. The parent's purpose should be to assist each child to grow and develop in a manner which is both, personality satisfying to the child and socially acceptable. Hence the knowledge of child rearing practices is important for Parents. It is to be seen that the educational level of parents directly influences the development of the child, because the personality is a product of hereditary potentialities and environmental forces. No significant work hap been done so far to analyze and project the effect of education level of parents 'on child rearing practices.

This study may have multifarious significant importance for parents, psychologists, and educationists. Every country is giving more and more importance to education of child development now a days. A lot of stress is being given to Adult education in this country. Educationists may teach the parents the better scientific method of child rearing practices. It may help psychologists to emphasise upon the parent to adopt the best child rearing practices. The comparative' study may reveal and help in devising best possible scientific methods of child rearing practices which may be helpful to parents to bring out a well developed Child.

\section{Aims and Objectives of the Study}

The following are the specific objectives of the study-

(i) To study the child rearing practices of the parents of low level of education.

(ii) To study the child rearing practices adopted by the parents of average level of education.

(iii) To study the child rearing practices of Highly Educated parents.

(iv) To compare the child rearing practices among the three levels of educated parents.

\section{Method \& Procedure}

Nine aspects of child rearing practices namely Breast feeding, weaning, toilet-training, play, rest and sleep, health, behaviour, demands and restrictions and education of the child were considered for the study.

Parents are classified into three study groups according to their education.

\subsection{Group I : Low Level of Education}

Parents having 'average' education upto 10 years of schooling; mothers having education only upto junior high school, i.e., upto 8th class.

\subsection{Group II : Average Level of Education}

Parents having 'average' education between 10 to 14 years of schooling; mothers having education between junior high school and intermediate or its equivalent.

\subsection{Group III : High Level of Education}

Parents having 'average' education over and above 14 years of schooling; mothers having education more than intermediate level, i.e., post secondary level.

\section{Tools and Techniques}

They consist of two separate schedules D and P for Peadiatricians/Gyneacologists and Psychologists respectively, related to different nine aspects of child rearing practices. Namely Breast feeding, weaning, toilettraining, play, rest and sleep, health, behaviour, demands and restrictions and education of the child were considered for the study.

The Schedule D meant for Peadiatricians and Gyneacologists 'was developed and constructed by the researcher to find out the ideal prenatal and perinatal child rearing practices. It contained 30 multiple choice questions regarding breast feeding, weaning, toilet training, bathing, health and hygiene etc. relevant to the study.

The Schedule P was meant for Psychologists. It was developed and constructed to prepare ideal practices related to child development and child psychology. To elicit the impact of sex of child on child rearing practices, separate questions for male and female child were included in the questionnaire. It consisted of 42 multiple choice questions related to behaviour, habit formation, rest and sleep, play, demands and restrictions, education of child etc. relevant to the study. 


\section{Sampling}

a. Schedule-D - 23 Peadiatricians and 23 Gyneacologists of Agra city were interviewed.

b. Schedule-P - 45 Psychologists were interviewed.

c. A preliminary survey of about 500 parents were carried out through a questionnaire to select the sample in each category of education level.

d. A questionnaire were designed for specific purpose for collecting information about the child rearing practices of parents of different levels of education.

\section{Delimitations}

Children within 2 years and 4 years of age were selected for the study, almost equal number of boys and girls were selected in each study group. Only non-working mothers of nuclear family belonging to urban population were selected. Study was conducted on parents of 'Average' Socio-Economic Status. Caste and Religion of parents were randomized. A questionnaire, consisting of total 64 multichoice questions on nine aspects of child rearing practices was developed after conducting the Pilot study by consulting relevant literature, available questionnaires/schedules and taking the guidance and opinion of the experts of different fields related to child rearing.

\section{Procedure}

"Preferential Sequence" given to each answer by the experts were tabulated for every question. For each answer 'weighted Preferential Index' (W.P.I.) was computed by applying 'Fuzzy Set' approach. The answer with maximum W.P.I. was considered as ideal child rearing approach for that question. These rearing practices were compiled as Ideal Rearing Practices (I.R.P.)

Reliability of questionnaire was computed using Kuder Richardson's formula No. 20 yielding $r_{t t}=$ 0.812 and in the opinion of experts the questionnaire had a moderate construct validity. A study was carried out to assess the demographic and socio-economic status of parents. Questionnaire was distributed to 927 parents and after delimitation and assessment of Socio-Economic Status of parents, 262 parents of average socioeconomic status of all the three study groups were selected for the study of child rearing practices. Questionnaire of child rearing practices was distributed to 262 parents (Group I-88; Group II-93 and Group III-81) of the three study groups. Out of 79, 87 and 79 completely filled questionnaire received in Group I, II and III respectively, 50 in each group were selected randomly.

\section{Statistics}

Chi-square analysis was made for each assertion wherever possible to determine the significant relationship between education of parents and child rearing practices. Differences among the parents of different levels of education were also analyzed.

A five point rating scale was used to assess the parents on five dimensions of child rearing practices, viz., Over-permissive, Permissive, Ideal, Rigid, Very Rigid. The scale of parental child rearing practices from extreme Very Rigid (Point 1) on one end to extreme Over-permissive on the other end (Point 5) with Ideal practices as mid point (Point 3) whereas Rigid and Permissive practices were assigned Point 2 and 4 respectively.

TABLE 1

Parents were classified in five categories of child rearing practices within the following limits.

\begin{tabular}{|c|l|c|c|}
\hline S. No. & Categories of Child rearing practices & Limits & Range of Scores \\
\hline 1. & Very Rigid & $-3.0 \sigma$ to $-1.8 \sigma$ & 169 to 178 \\
\hline 2. & Rigid & $-1.8 \sigma$ to $-0.6 \sigma$ & 179 to 188 \\
\hline 3. & Ideal & $-0.6 \sigma$ to $+0.6 \sigma$ & 189 to 198 \\
\hline 4. & Permissive & $+0.6 \sigma$ to $+1.8 \sigma$ & 199 to 209 \\
\hline 5. & Over-Permissive & $+1.8 \sigma$ to $+3.0 \sigma$ & 210 to 219 \\
\hline
\end{tabular}

Finding of classification of parents of all the three levels of education in various categories, viz., Very Rigid, Rigid, Ideal, Permissive, Over-permissive of child rearing practices is summarized.

\section{Analysis and Interpretation}

TABLE 2

\begin{tabular}{|l|c|c|c|c|c|c|c|c|}
\hline \multirow{2}{*}{ Categories } & \multicolumn{2}{|c|}{ Group - I } & \multicolumn{2}{c|}{ Group - II } & \multicolumn{2}{c|}{ Group - III } & \multicolumn{2}{c|}{ Total } \\
\cline { 2 - 9 } & $\mathbf{N}$ & $\mathbf{\%}$ & $\mathbf{N}$ & $\mathbf{\%}$ & $\mathbf{N}$ & $\mathbf{\%}$ & $\mathbf{N}$ & $\mathbf{\%}$ \\
\hline Very Rigid & - & - & 1 & 2 & 2 & 4 & 3 & 2.00 \\
\hline Rigid & 7 & 14 & 12 & 24 & 16 & 32 & 35 & 23.33 \\
\hline
\end{tabular}




\begin{tabular}{|l|c|c|c|c|c|c|c|c|}
\hline Ideal & 21 & 42 & 26 & 52 & 23 & 46 & 70 & 46.67 \\
\hline Permissive & 17 & 34 & 11 & 22 & 8 & 16 & 36 & 24.00 \\
\hline $\begin{array}{l}\text { Over- } \\
\text { Permissive }\end{array}$ & 5 & 10 & - & - & 1 & 2 & 6 & 4.00 \\
\hline Total & 50 & 100 & 50 & 100 & 50 & 100 & 150 & 100.00 \\
\hline
\end{tabular}

Analysing the child rearing practices of parents of three study groups it was found that 21 parents out of 50 of Group I followed ideal rearing practices as compared to 26 and 23 of Group II and III respectively. Total 70 parents of all the three groups were found to be ideal in rearing practices. Almost equal number, 35 and 36 parents of all the three groups deviated to Rigid and Permissive rearing practices respectively. 7, 12, and 16 of Group I, II and III receptively were found to be rigid, whereas 17, 11 and 8 of Group I, II and III respectively were permissive in rearing practices. A few parents of all the three groups followed very rigid or over permissive rearing practices. Only 3 parents ( 1 of group I and 2 of group III) were to be Very Rigid, whereas 6 parents ( 5 of Group I and one of Group III) were found to be over permissive $\cdot$ in rearing practices. It is observed that parents of higher level of education tend to deviate to rigid practices, whereas parents with low level of education deviate to permissive practices. Only 46.67 percent parents of all the three levels of education follow ideal rearing practices.

The descriptive analysis of the data and justification on the basis of collective opinions of the experts and interaction with them for I.R.P. on nine aspects (breast feeding, weaning, toilet training, play, rest and sleep. health, behaviour, demands and restrictions and education of the child) of child rearing practices are given below in table No. 3 .

TABLE 3

Classification of Parent in Various Categories of Child Rearing Practices

\begin{tabular}{|c|c|c|c|c|c|c|c|c|c|c|c|c|c|c|c|c|c|c|c|c|c|}
\hline \multirow{2}{*}{$\begin{array}{c}\text { S. } \\
\text { No. }\end{array}$} & \multirow{2}{*}{ Areas } & \multicolumn{5}{|c|}{ Group -I } & \multicolumn{5}{|c|}{ Group -II } & \multicolumn{5}{|c|}{ Group -III } & \multicolumn{5}{|c|}{ Total } \\
\hline & & VR & $\mathrm{R}$ & I & $\mathrm{P}$ & $\mathrm{OP}$ & VR & $\mathrm{R}$ & I & $\mathrm{P}$ & $\overline{\mathrm{OP}}$ & \begin{tabular}{|l|} 
VR \\
\end{tabular} & $\mathrm{R}$ & I & $\mathrm{P}$ & $\mathrm{OP}$ & VR & $\mathrm{R}$ & I & $\mathrm{P}$ & $\mathrm{OP}$ \\
\hline 1. & Overall & - & 7 & 21 & 17 & 5 & 1 & 12 & 26 & 11 & - & 2 & 16 & 23 & 8 & 1 & 3 & 35 & 70 & 36 & 6 \\
\hline 2. & Breast F & 2 & 11 & 22 & 12 & 3 & - & 16 & 19 & 14 & 4 & - & 20 & 18 & 10 & 2 & 2 & 47 & 59 & 36 & 6 \\
\hline 3. & Wea & - & 1 & 17 & 22 & 10 & - & 30 & 20 & - & - & 1 & 23 & 25 & 1 & - & 1 & 54 & 62 & 23 & 10 \\
\hline 4. & Toil & - & 11 & 21 & 14 & 2 & - & 13 & 23 & 13 & & 1 & 21 & 17 & 9 & 2 & 1 & 45 & 61 & 36 & 7 \\
\hline 5. & Play & 1 & 7 & 28 & 11 & 3 & 3 & 7 & 31 & 7 & & 2 & 6 & 32 & 6 & 4 & 6 & 20 & 91 & 24 & 9 \\
\hline 6. & Rest ar & 3 & 12 & 25 & 7 & 3 & 3 & 7 & 29 & 8 & & 2 & 12 & 29 & 5 & 2 & 8 & 31 & 83 & 20 & 8 \\
\hline 7. & Health & - & 8 & 20 & 18 & 4 & - & 17 & 24 & 9 & - & - & 28 & 17 & 4 & 1 & - & 53 & 61 & 31 & 5 \\
\hline 8. & Beha & 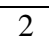 & 11 & 23 & 12 & 2 & 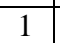 & 12 & 28 & 8 & & 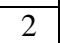 & 9 & 28 & 11 & - & 5 & 32 & 79 & 31 & 3 \\
\hline 9. & $\begin{array}{l}\text { Dem } \\
\text { Restr }\end{array}$ & 3 & 19 & 13 & 14 & 1 & 6 & 6 & 17 & 19 & 2 & 1 & 12 & 11 & 25 & 1 & 10 & 37 & 41 & 58 & 4 \\
\hline 10. & Education & 2 & 12 & 23 & 12 & & 1 & 13 & 23 & 10 & $J$ & & 11 & 20 & 14 & 5 & 3 & 36 & 66 & 36 & 9 \\
\hline
\end{tabular}

VR = Very Rigid; $\mathrm{R}=$ Rigid; I = Ideal; $\mathrm{P}=$ Permissive; OP = Over Permissive

\section{a. Breast feeding}

It is revealed that infant (neonate) should be put to breast for the first feed between 4 to 8 hours of birth. The W.P.I. for first feed, after 4 hours was found to be 3.47" (maximum) followed by after 8 hours of birth as 2.35. According to the opinions of the experts the child when born, comes to an entirely new environment and requires certain time for adjustment to it; also some time is required to clear up the digestive track of the child. At the same time, early first feed is advised since at the time of delivery (or in some cases before the delivery) the breast of the mother start secreting a vital yellow colour, thick pre-milk fluid known as 'colostrum'. This natural gift is rich in proteins contains low fat contents, and all the vitamins required for new born. Besides these, it has anti-body characteristics to protect the infant from various infections. The actual milk starts after 3 to 4 days of the birth, till then, baby must be fed with this vital fluid-colostrum, rather than discarding it and feeding the baby with other pre-lacteal supplementary liquid foods, like water with sugar, honey, water with glucose etc. The Child put earlier on breast, comes in physical contact with mother-feeling secured and emotionally stable, thereby adjusting to new environment without any difficulty.

The experts recommend the pattern of schedule feeding (W.P.I. 10.6) to demand feeding (W.P.I. 7.84) with 5 to 6 feeds a day (2-3 hours time interval between two feeds) upto 3 months of the age of the child; 4 to 5 feeds a day upto 3-6 months of age and 3-4 feeds after 6 months of age-that is, the time interval between two feeds should be increased with increase in the age of the child. It is advised that mother should take preferably some nourishing liquid diet like milk, fruit juice etc. before feeding the child. This not only makes the flow of milk easy but feeds the child with proper nutrients, since whatever mother eats (even the medicines) is ingested by the child through the breast milk. The practice of taking liquid diet also serves as a rehydrating agent to mother. The diet taken by the mother should be rich in vitamin $\mathrm{C}$, since the only vitamin which mother's milk lacks, is vitamin C. If due to some reason, it is not possible to take liquid diet then some semi-solid diet like- 
green vegetable, 'fruits' 'dalia', 'dal' etc. may be taken. The total duration of the breast feeding as per the opinion of the experts should not be less than 9 months (W.P.I. 4.12) and if possible may continue upto 12 months (W.P.I. 3.91). In ideal case breast feeding should be stopped only due to age of the child (W.P.I. 5.91) other reasons may be pregnancy (W.P.I. 4.23) and lack of sufficient lactation (W.P.I. 4.23) etc.

\section{b. Weaning}

Weaning is a process of introducing supplementary food other than breast milk into the diet of the child ultimately to give up suckling. In the opinion of the experts, the supplementation of food should be done gradually and not abruptly. They feel that complete weaning process may take 2-3 years, and may be done in two phases as weaning from breast to bottle to introduce top milk in case of lack of sufficient lactation, and from bottle to cup to give up suckling.

Ideally top milk may be introduced between 3-6 months of age of the child (W.P.I. 4.23) that is Child should be exclusively breast fed for 3 months (W.P.I. 2.3 for introducing top milk before 3 months). At the same time introduction of top milk should not be delayed after six months (W.P.I. 2.62) since lactation from mother's breasts may not be sufficient to meet the nutritional demands of the growing child. The experts now a days feel that bovine milk (especially cows milk-W.P.I. 4.08) should be preferred than commercial formula milk (W.P.I. 2.63) as top milk. They were divided in their opinion regarding the dilution of top milk (bovine milk) by mixing water-about half the experts did not recommend dilution of milk stating it is not hygienic and causes gastroenteritis, infections, diarrhoea etc. whereas other half of the experts were of the opinion that the milk be diluted by mixing boiled water and decreasing the proportion of water (volume wise) with age of the child. The W.P.I. could not be computed since tile experts with first opinion did not give 'Preferential Sequences' to the answers of the question. Use of milk bottles may be continued upto 1 year of age of the child (W.P.I. 3.80) but prolonged use of milk bottles, even after one year of age (W.P.I. 2.10) may create problems and difficulties for second phase of the weaning that is, from bottle to cup. Milk bottle should always be cleaned by boiling it (W.P.I. 16.2) rather than by any other method. After 3 months of age of the child, beside the top milk, various types of supplementary foods may be introduced into the diet of the child to develop taste and likings and to meet the nutritional requirements of the growing Child. The recommended ideal age of the child for introduction of various supplementary foods (with maximum W.P.I.) depicted by single asterisk (*) is given in Table 4. It is an idea: practice to try variety of supplementary foods to develop the taste and likings for the food.

TABLE 4

Weighted Preferential Index for Supplementary Foods

\begin{tabular}{|l|c|c|c|c|c|c|}
\hline \multirow{2}{*}{$\begin{array}{c}\text { Supplementary } \\
\text { Food }\end{array}$} & \multicolumn{7}{|c|}{ Age of the Child } \\
\cline { 2 - 7 } & $0-3$ months & $3-6$ months & $6-9$ months & $9-12$ months & 12 months above & Not given \\
\hline Fruit Juice & 1.41 & $1.42^{*}$ & 1.21 & 1.22 & 1.10 & 1.00 \\
\hline Meshed Fruit & 1.21 & 3.30 & $9.30^{*}$ & 6.30 & 1.10 & 1.00 \\
\hline Soup & 4.00 & 14.50 & 10.30 & 5.43 & 1.21 & 1.00 \\
\hline Egg & - & - & $2.31^{*}$ & 2.12 & 1.10 & 1.00 \\
\hline $\begin{array}{l}\text { Daliya, Daal, } \\
\text { Khichedi etc. }\end{array}$ & 1.30 & 2.91 & $3.40^{*}$ & 2.93 & 2.13 & 1.00 \\
\hline Biscuit & 1.10 & 1.20 & $1.62^{*}$ & 1.40 & 1.50 & 1.00 \\
\hline Bread Toast & 1.03 & 1.02 & $1.54^{*}$ & 1.60 & 1.00 & 1.00 \\
\hline Chapati & - & - & 1.54 & $1.60^{*}$ & 1.45 & 1.00 \\
\hline Baby Food & 13.00 & $12.97^{*}$ & 11.20 & 7.22 & 3.31 & 1.00 \\
\hline Green Veg. & 1.11 & 8.50 & $9.50^{*}$ & 7.22 & 5.10 & 1.00 \\
\hline Curd & 1.20 & 2.60 & $3.81^{*}$ & 2.81 & 1.07 & 1.00 \\
\hline Kheer & 1.12 & $6.80^{*}$ & $6.80^{*}$ & 2.10 & 1.20 & 1.00 \\
\hline Besan Laddu & 1.00 & 2.30 & $6.82^{*}$ & 3.10 & 3.30 & 1.00 \\
\hline Halwa & 1.00 & 2.20 & $6.18^{*}$ & 3.12 & 2.24 & 1.00 \\
\hline Cheese & 2.33 & 2.33 & $4.00^{*}$ & 2.60 & 1.00 & 1.00 \\
\hline Boiled Potato & 1.00 & 1.00 & $6.00^{*}$ & .3 .60 & 2.10 & 1.00 \\
\hline
\end{tabular}

\section{* Ideal Practices}

\section{c. Toilet Training}

The proper training of young child to control defecation and urination so as to release them at proper place and time plays an important role in Child rearing practices. According to the experts parents should be very conscious about the age at which toilet training should be started though many parents over enthusiastically, start toilet training earlier (as soon as child starts sitting), but in the opinion of the experts this 
not only prolongs the duration of accomplishment of training and create difficulties for the child but also causes emotional disturbances to the child. The ideal age recommended for toilet training is towards the end of 1 year of age or just after. It is advised that parents should keep patience in the toilet training of the child and should not make haste in it, child may be trained with love and affection by following regular schedule (W.P.I. 2.43) rather than giving stress for toileting at proper place (potty seats etc. WP.I. 1.85).

The experts are of the opinion that in toilet training, child should be helped by mother (W.P.I.4.3) rather than by any other family member (W.P.I. 1.57) or 'Ayaa' servant (W.P.I. 1) this is stressed because of several reasons: toilet training starts at the age when breast feeding is stopped and weaning starts, child feels detached from the mother and if at this period, mother starts avoiding the child by reducing her involvement into activities of the child, the gap between child and mother widens-thereby child may get disturbed emotionally; similarly the proper care which a mother can give to her child with love and affection, cannot be given by any other family member or servant.

The experts opine that to prevent bed wetting, parents should use "Momjaama" (Macintosh) covered with cotton cloth (W.P.I. 1.34) rather than using nylon nappies (WP.I. 3.21) which may cause nettle rashes and other skin infections to tender and delicate skin of the child. If the child continued to be wet even after certain age, it is recommended that child should not be scolded or neglected (W.P.I. 1.0) rather than child should be made to understand with love (W.P.I. 16.5) any dry nights should be suitably rewarded (W.P.1. 16.5) or advice of a doctor should be sought (WP.I. 13.5).

In the opinion of the experts the child may be massaged before bathing, occasionally (W.P.I. 3.81) rather than daily (W.P.I. 2.1). The toiletries of the child should be kept separate (exclusively) and other family' members should not be allowed to use them. Fixed schedule of bathing is preferred to form the bathing habits of the Child.

\section{d. Play}

It is a well established fact that, play is an important activity for cognitive and motor development of the child. The experts feel that parents should be conscious about providing the child with age appropriate toys occasionally (W.P.I. 3.07) rather than always or never (W.P.I. 2.1 and 1.0 respectively). The arguments given in this respect vary from difficulty in deciding the age appropriate toys, limiting the scope of learning of the Child by always providing with age appropriate toys and so on. The child should be trained to keep the toys at proper place with love, Child should, sometimes, be given complete freedom to play, rather than always or never. This is advocated to monitor the play activities of the child. If the child does not play according to likings of parents, he/she should be made to understand with love (W.P.I. 3.17) rather than scolding (W.P.I. 1.3) or diverting the attention of the child (W.P.I. 2.10). Parents (both mother and father) should, sometimes, involve themselves in the play of the child.

\section{e. Rest and Sleep}

In the opinion of the experts it is an ideal practice to make the Child sleep according to a fixed schedule. It is preferred that the child should sleep with mother (W.P.I. 3.1) rather than with any other family member. No fixed schedule should be followed for waking up the child. Ideally, child should be made to sleep during the day regularly (W.P.I. 3.72).

\section{f. Health}

It is recommended that during pregnancy, mothers should take tetanus taoxide (T.T.) vaccine to protect the child and herself against tetanus infection during and after delivery. Full term birth of the child is considered an ideal birth (W.P.I. 10.91) against premature (W.P.I. 1.0) or over due (W.P.I. 6.13). The ideal (normal) birth weight of tile child was found to be between $2^{1 / 2} \mathrm{Kg}$. to $3 \mathrm{Kg}$. children with low birth weight need more care in rearing, whereas children with over weight may create complications at the time of delivery. The weighted preferential index for immunization schedule could not be computed since every expert (Peadiatrician/ Gynaecologists) recommended the standard schedule published by WHO. Regarding the ideal age of achieving various milestones, the values of W.P.I.'s are given in Table 5. It is found that child must have first teething, and start sitting between 6-9 months of age, whereas the child should learn to speak first word, crawling and walking with support between 9 to 12 months of age, and should learn walking without any support between 12 to 15 months of age.

The experts recommend the use of soft cotton clothes (preferably made even out of old-used clothes) rather than made of silken, polyster, nylon or terrycot etc. Precautions should be taken to get these cloths stitched with loose fitting. The mother should take proper care regarding the health of the child so that he/she may not fall sick due to unhygienic conditions, dirty milk and water or food etc. The child may be trained to form the habits of cleanliness with love and affection (W.P.I. 3.21) or by creating interest towards the cleanliness (W.P.I. 4.16) the experts opine that habits of 'pica'- ingestion of indigestible things should be handled carefully. Since it is caused because of Psychological as well as nutritional problems. Child with Pica 
should never be ignored (W.P.I. 1.0) or beaten or scolded (W.P.I. 1.3) rattler, doctor's advice must be sought (W.P.I. 17.76) and the child should be treated with love and affection (W.P.I. 12.3) to prevent this habit.

TABLE 5

Weighted Preferential Index for Milestones

\begin{tabular}{|l|c|c|c|c|c|}
\hline \multirow{2}{*}{\multicolumn{1}{|c|}{ Activities }} & \multicolumn{5}{c|}{ Age of the Child } \\
\cline { 2 - 6 } & $\begin{array}{c}6-9 \\
\text { months }\end{array}$ & $\begin{array}{c}9-12 \\
\text { months }\end{array}$ & $\begin{array}{c}12-15 \\
\text { months }\end{array}$ & $\begin{array}{c}15-18 \\
\text { months }\end{array}$ & $\begin{array}{c}18 \text { months } \\
\text { above }\end{array}$ \\
\hline Start teething & 6.00 & 3.10 & 1.12 & 1.00 & - \\
\hline Start sitting & $6.02^{*}$ & 4.23 & 2.14 & 1.00 & - \\
\hline Pratham shabd mama, papa bolna & 1.20 & $6.20^{*}$ & 5.30 & 2.13 & 1.00 \\
\hline Crawling & 1.30 & $3.54^{*}$ & 1.10 & 1.00 & 1.00 \\
\hline Walking with support & 2.14 & $7.81^{*}$ & 3.21 & 1.00 & 1.12 \\
\hline Walking without support & - & 1.00 & $7.15^{*}$ & 6.29 & 3.14 \\
\hline
\end{tabular}

\section{*Ideal Practice}

\section{g. Behaviour}

It is observed from the above findings that if the parents deviate from ideal practices to rigid or permissive practices they have more 'Chanchal' (frolicsome) children (Rigid-71.42\%, Ideal-47.14\%, Permissive-52.77\%). Children of parents following Ideal rearing practices were found to be more 'Milasaar' (sociable) - $21.42 \%$, as compared to parents following Rigid practices (17.14\%) and Permissive practices (11.11\%). It is obvious that as the parents deviate from Rigid to Permissive rearing practices the percentage of 'Sharmila' (shy) children increase-5.71, 10 and 19.44 percent children were reported to be 'Sharmila' (shy) with Rigid, Ideal and Permissive rearing practices, whereas 5.71, 11.4 and 13.8 percent children were found to be 'Jiddi' (obstinate). Very negligible number of children of educated parents were reported to be 'Irshyalu' (jealous) and "chirchida' (irritable) or 'Udaseen' (apathetic) in nature irrespective of types of rearing practices adopted by the parents. It can be stated that ideal rearing practices are desirable to make the child less 'Chanchal' (frolicsome) more 'Milansaar' (sociable) and 'Sahayogatmak' (cooperative). Whereas Rigid rearing practices are helpful in reducing the tendency of 'Sharmila' (shyness) and 'Jiddi' (obstinate) behaviour of the child.

\section{h. Demands and Restrictions}

According to the opinions of the psychologists, parents should train the child with their own example (W.P.I. 3.66) rather than by using strict disciplinary techniques (W.P.I. 1.0). The child should be given freedom to talk to other persons occasionally (W.P.I. 2.62) rather than always or never. No attention should be paid to unreasonable demands of the child. If the child shows resentment for not getting tile demands fulfilled the parents should make the child understand with love. Ideal way of punishing the child, according to the psychologists, is to stop talking (boycot W.P.I. 3.33) to the child rather than scolding (WP.I. 2.91) or beating (W.P.I. .0) etc.

\section{i. Education}

For the age group (2-4 years) of the child, considered for the study, experts opine that Child should be able to read 3 to 10 words. Teaching the child through story books, rhymes etc. is preferred by the experts to the play way method. Mother as well as father should involve themselves occasionally to teach the child. Child should be sent to school in the beginning with love and affection rather than using lucrative methods or sending forcefully. Parent should take care of making all arrangements (school bags, tiffin box, conveyance etc.) for school daily. If the child shows unwillingness in going to school, he/she should be sent by making him understand with love and affection.

\section{Conclusion}

It is clear that most of the educated parents, irrespective of their levels of education do not always follow ideal child rearing practices. They are not up to the mark in same important aspects of child rearing like introduction of supplementary foods follow-up proper immunization schedule and in achievement of various milestones by the child at proper (ideal) age. All the same education of parents has significant effect on their adoption of various categories of child rearing practices. There was no significant relationship between parents of different level of education \& their adoption of ideal child rearing practices. It is, therefore, inferred that the role of modern education, as a vehicle of social enlightenment, tends to shatter not unexpectedly the existing traditional perceptions and conception of what are regarded as ideal practices. This makes the more enlightened to seek new inputs in the education deviating significantly for what is classical, conventional or dogmatic about the ideal practices. It is symbolic of state of flu in social and educational perceptions. 


\section{Scope of Study}

It is hoped that the finding of the study will be utilized by these concerned with child welfare. In compliance with the recent policy and efforts of Government and various agencies towards the child care and child development, the study may prove to be useful in the following multifarious way :-

1. The study may be helpful to unfold the existing knowledge and trends of child rearing practices adopted by educated parents so that guidance may be provided to improve them.

2. The study may be helpful to educationists and child psychologists to evolve better easy-to-adopt, scientific patterns of child rearing practices with empirical confirmation.

3. The study may help the parents to learn the desirable way of child rearing practices, to improve upon the existing stereotype traditional child rearing practices.

4. The study may help in bridging the gap between the ideal and existing child rearing practices.

5. The study may help in determining what parents transmit to their child and how.

6. It may help to improve the curriculum in schools and colleges - especially for girls, regarding teaching mother craft and child health care.

7. It may serve as a guideline to improve the behaviour of the child through rearing practices.

8. The study may serve as a representative "feed back" to different agencies engaged in the tasks of the child care and child development, which may help them to asses the outcomes of their efforts put in so far.

9. It may help to modify and channelize the programmes of child care in future for better co-ordination between parents and agencies involved in child care.

[1] Jersild, A.T., Woodyard, E.S., and Del, Solar, C.F. Joy and problem of child rearing. Columbia University Press, New York. (1949).

[2] Whiting, J.W.M., and Child, I.L. Child training and personality : A cross-cultural study. New Haven Conn. Yale University Press. (1953).

[3] Watson, G.B. Some personality differences in children related to strict or permissive parental discipline. Journal of Psychology, 44 (33) : (1957). 227-249.

[4] Sears, R.R., Maccoby, E.E., and Levin, H. Patterns of child rearing. New York : Harper and Row, Peterson and Co. (1957)

[5] Hurbert, M.A.G. and Britton, J.H. Attitude and practices of mother rearing their children from birth to the age of two years, Journal of Home Economics, 49 (208), (1957). p. 219.

[6] Best, W.J. Research in education. Englewood : Prentice Hall, (1959).

[7] Brim, O.G. Education for child rearing. The Free Press, New York, (1959).

[8] Garrett, H.E., and Woodworth, R.S. Statistics in Psychology and Education(4 ${ }^{\text {th }}$ Ed.). Bombay : Vakil, Ferrer and Simons Ltd. (1967).

[9] Dinkmeyer, D.C. Child Development : the emerging self. New Delhi : Prentice Hall. (1965).

[10] Wise, S.J., and John, E. Methods of Research in Education. Massachusetts : D.C. Health and Company. (1967).

[11] Atit, R., Anandan, K., and Chandramani. Relationship of parental attitudes to social behaviour of children in nursery school. The Indian Journal of Home Science, 2 (2), (1968). 118-121.

[12] Devi, R.N. Child rearing practices in rural families of two income levels. The Indian Journal of Home Science, 2 (1), (1968). $44-47$.

[13] Jhonson, R.C. and Medinnus, G.R. Child Psychology : Behaviour and Development ( $2^{\text {nd }}$ Ed.). New York : John Wiley Sons. (1968).

[14] Suseela, K., Devi, R.N. and Devadas, R.P. Child rearing practices of employed and non-employed mothers. Indian Journal of Home Science, 4 (2) : (1970). 101-104

[15] Spencer, T.D., and Kass, N. Perspectives in Child Psychology (Research and Review). London McGraw Hill Book Company. (1970).

[16] Praveen, S. Indira, R. and Devdas, R.P. Cross-cultural study of child rearing practices in Badags \& Irulas in Nilgri \& Combatore Districts. Indian Journal of Home Science, 4 (1) : (1970). 51-56.

[17] Joshi, M.C. and Tiwari, J. Personality development of children in relation to child rearing practices among socio-economic classes. Indian Psychological Review, 14 (4), (1977). 5-15.

[18] Aphole,C.A. Child in home and school : A study of upbringing of children in a Maharashtrian Hindu Families in Poona. (Doctoral dissertation, University of Poona, 1962) Second Survey of Educational Research; Baroda, M.B. Buch. (Ed). (1978). 86.

[19] Hurlock,E.B. Child Development (6 ${ }^{\text {th }}$ Ed.). Tokyo : McGraw Hill. Kogakusha. (1978).

[20] Banner, C.N. Child-rearing attitudes of mothers of under; average and overachieving children. British Journal of EducationalPsychology, 49, (1979). 150-155.

[21] Juneja, R. A comparative study of working and non-working mothers with regard to practices and problems of rearing children. Indian Psychological Review, 18 (1), (1979). 20-24.

[22] Phatak. P. Practices and Problems of rearing children. Indian Psychological Review, 18 (1-4), (1979). 45-48

[23] Wester, C.D., Konstantarcas, M.M., Oxman, J. and Mack, J.E. Austim : New Directions in Research and Education. New York : Perfaman Press. (1980).

[24] Farren, D.C., and Huskins, R. Reciprocal influence in the social interactions of mothers and three-year-old children from different socio-economic backgrounds. Child Development, 51 (3), (1980).780-791.

[25] Kennedy, M.L. A longitudinal study of the development of rearing behaviour in pre-school child (doctoral dissertation, University of Cornell, 1979). Dissertation Abstracts International, 41 (3), (1980). 984-A

[26] Kishore, G.S., Roy, R.N., and Pandey, N.K. Sex difference in child rearing patterns. Indian Psychological Review, 19 (2), (1980). 56.

[27] McCandless, B.R., and Trotter, R.J. Children Behaviour and Development ( $3^{\text {rd }}$ Ed.). New York :Halt Rinchart and Winston. (1981).

[28] Singh, M.B., and Kaur, S. Mother-child interaction in rural and urban areas. Indian Psychological Review, 20 (2), (1981). 7-16.

[29] Jhonson, D.M. Some characteristics of mothers and fathers in parent child play (Doctoral Dissertation, University of Maryland, 1981). Dissertation Abstracts International, 42 (8), (1982). 3428-A.

[30] Stephen, J. Child beating a cross cultural study. (Doctoral dissertation, University of California, 1981). Dissertation Abstracts 
International, 42 (2), (1982). 557-A.

[31] Awasthi, N.N. Kaushik, A., and Mathur, B.D. Feeding and rearing practices in rural area of Jhansi-Bundelkhand. The Indian Journal of Pediatrics, 50 (402), (1983). 33-37.

[32] Roberts, G.C., Block, J.H. and Block, J. Continuity and change in parents child rearing practices. Child Development, 55 (2) : (1984). 586-597.

[33] Bronfenbrenner, U., Alvarez, W.F., and Henderson, C.R. Working and watching : Maternal employment status and parents perceptions of their three-year-old children. Child Development, 55 (4), (1984). 1362-1378.

[34] Agarwal, D.K. Maternal and child health profiles of Varanasi division. Varanasi : Bhargava Bhushan Press, (1985).

[35] Mishra, C.P., Ready, D.C.S., And Tiwari, I.C. Some dietary beliefs and practices influencing growth in pre-school children of a backward community. The Indian Journal of Nutritions and Dietetics, 22 (12), (1985). 354-359.

[36] Choudhary, M., and Parashar, M. Weaning foods and feeding practices of urban and rural and tribal children. The Indian Journal of Home Science, 16 (2-3), (1986). 166-169.

[37] Cotterell, J.L. Work and Community influences on the quality of child rearing. Child Development. 57 (2), (1986). $362-374$.

[38] Tamer, S.K., Mehta, P.K., Warey, P., Tamer, U., and Swarnkar, J.S. A study on working educational mothers and its impact on child health. The Indian Journal of Pediatrics, 53 (5), (1986). 657-663.

[39] Bhal, L., and Kaushal, R.K. Infant rearing practices and beliefs in rural inhabitants of Himachal Pradesh. Indian Pediatrics, 24 (10), (1987). 903-906.

[40] Bathija, C.G. and Anand, R.K. Effect of Perinatal motivation on breast feeding in educated mothers. Indian Pediatrics, 24 (10) : (1987), 933-937.

[41] Gupta, S.C. Infant food supplementation. Impact of health education. Journal of Indian Education (N.C.E.R.T.), 13 (1), (1987). 6367.

[42] Maikandan, D. Wastage of Colostrum. Indian Pediatrics, 28 (10), (1987). 952.

[43] Prabhakaran, G.N., Awasthi, P.V., Shivram, C., and Viswanath, A.N. Infant feeding patterns in slums of Bangalore. Indian Pediatrics, 24 (10), (1987). 895-898.

[44] Vimla, V. and Ratnaprabha, C. (1987). Infant feeding practices among tribal communities of Andhra Pradesh. Indian Pediatrics, 24 (10), 907-910.

[45] Walia, B.N.S., Gambhir, S.K., Arora, S.N., and Chaudhary, S. Decline in breast feeding practices in urban population of Chandigarh during a decade. Indian Pediatrics, 24 (10), (1987). 879-889.

[46] Ahamed, M.M. Breast-feeding patterns in Bangladesh. The Journal of family welfare, 34 (4), 1988, 36-44

[47] Goswami, A. The study of changing patterns of child rearing practices of first and later-born children in relation to socio-economic and cultural aspects. Unpublished doctoral dissertation. Agra University, Agra, (1988).

[48] Padmini, I.K., and Krishnamoorthy, S. Differences in breast feeding practices between family types in a Tamil Naidu Village. The Journal of Family Welfare, 35 (1), (1988). 61-64.

[49] Srivastava, J.N., and Saksena, D.N. Immunization of children and its correlates in rural Uttar Pradesh. The Journal of Family Welfare, 35 (1), (1988). 22-23.

[50] Awasthi, S., Mishra, P.K., and Malik, G.K. Morality in early infancy in relation to feeding practices. Proceedings of XXVI National Conference. Indian Academy of Pediatrics, Agra (India), (1989).

[51] Balachandran, A., Somu, N., Subramanyam, L. Vijayasekaran, D. and Kamla, K.G. Influence of child rearing practices in children with persistent recurrent. Pneumonia. Proceedings of XXVI National Conference. Indian Academy of Pediatrics, Agra (India). (1989).

[52] Inamadar, S. and Mehta, R. Ideal age for completion of weaning. Proceedings of the XXVI National Conference Indian Academy of Pediatrics. Agra (India). (1989).

[53] Singhal, P.K. Advantages of breast feeding-knowledge, paramedical health personnal \& mothers. Indian Pediatrics, 26 (5) : (1989). $492-495$. 